\title{
PENGEMBANGAN DESAIN MESIN ROASTER KACANG TANAH DENGAN METODE QUALITY FUNCTION DEPLOYMENT
}

\author{
Sanny Andjar Sari ${ }^{1}$, Salammia $\mathbf{L A}^{2}$, Sri Indriani ${ }^{3}$ \\ 1,2,3 Program Studi Teknik Industri, Institut Teknologi Nasional Malang \\ sannysari@lecturer.itn.ac.id
}

\begin{abstract}
Abstrak. Home industry yang terletak di Jl. Sidoluhur RT 07 RW 01, Kepanjen - Malang, bergerak dalam industry olahan pangan yaitu "Kacang Goreng" home industry ini berdiri mulai tahun 2000. Pada proses pembuatan kacang goreng salah satu tahapannya yaitu proses penyangraian. Pada proses penyangraian masih menggunakan wadah yang terbuat dari tanah liat dengan bahan bakar kayu.
\end{abstract}

Pada dasarnya proses penyangraian kacang menggunakan wadah yang terbuat dari tanah liat dengan bahan bakar kayu tersebut memakan waktu sangat lama yaitu $1-2$ jam sedangkan untuk hasil produksi yang di peroleh dengan waktu $1-2$ jam tersebut hanya dapat mencapai $2 \mathrm{~kg}$ kacang tanah sedangkan permintaan pasar dalam sehari dapat mencapai $30 \mathrm{~kg}$ kacang tanah. Posisi penyangraian kacang tanah beban terberat terdapat pada punggung pekerja karena dilakukan dengan duduk yang sangat rendah, sehingga bagian punggung pekerja akan mudah sakit dan lelah, wadah penyangrai kacang dengan bahan bakar kayu untuk saat ini masih sangat sederhana sehingga tidak dapat memenuhi jumlah permintaan konsumen karena proses penyangraian menggunakan wadah penyangrai dari bahan tanah liat yang berbahan bakar kayu tersebut sangat lama. Karyawan yang bekerja di home industry tersebut hanya ada 2 orang sehingga untuk dapat menghasilkan produksi yang banyak akan kekurangan tenaga.

Tujuan penelitian ini yaitu merancang mesin roaster guna mengoptimalkan proses penyangraian kacang tanah dan bisa digunakan untuk biji-bijian lainnya. Metode yang digunakan pada penelitian ini yaitu dengan metode Quality Function Deployment. Quality Function Deployment adalah suatu pendekatan untuk mendesain produk agar dapat memenuhi keinginan pengguna dalam hal ini pengrajin produksi kacang goreng.

Kata kunci : $Q F D$, proses penyangraian, kacang tanah

\section{PENDAHULUAN}

Proses penyangraian kacang tanah saat ini masih membutuhkan waktu yang cukup lama dan dengan kapasitas produksi $1-2$ jam tersebut hanya dapat mencapai $2 \mathrm{~kg}$ kacang tanah, sedangkan permintaan pasar dalam sehari dapat mencapai $30 \mathrm{~kg}$ kacang tanah. Selain itu posisi penyangraian kacang tanah beban terberat pada punggung pekerja karena pada proses penyangraian dilakukan dengan duduk yang sangat rendah, sehingga bagian punggung pekerja akan mudah sakit dan lelah. Wadah penggorengan berupa wajan dari tanah liat yang berbahan bakar kayu untuk saat ini masih sangat sederhana sehingga tidak dapat memenuhi jumlah permintaan konsumen. Dari kondisi tersebut perlu dilalukan suatu pengembangan desain mesin roaster (penyangrai) kacang tanah untuk mempercepat dan menyamankan operasional pengguna dalam hal ini para pekerja pada home industry kacang goreng tersebut.

Rumusan masalah dalam penelitian ini yaitu bagaimana mengembangkan desain mesin roaster (penyangrai) kacang tanah dengan menggunakan metode Quality Function Deployment (QFD) ?

Adapun tujuan penelitian sebagai berikut :

Mengembangkan desain mesin roaster (penyangrai) kacang tanah dengan metode Quality Function Deployment (QFD).

Penelitian ini mempunyai kegunaan sebagai berikut:

1. Mempermudah dalam proses penyangraian kacang tanah.

2. Mempercepat dalam proses penyangraian kacang tanah.

3. Memperbanyak hasil produksi kacang goreng. 
Prinsip QFD adalah memastikan bahwa kebutuhan dan keinginan konsumen dapat terpenuhi dalam proses penguraian suatu produk atau jasa dan menemukan tanggapan inovatif terhadap kebutuhan guna memperbaiki proses hingga tercapai efektivitas maksimum. Untuk kebutuhan tersebut maka diperlukan data yang diperoleh dari hasil riset melalui berbagai cara seperti penyebaran dan pengumpulan angket terhadap konsumen baik intern (konsumen pembuat produk) maupun ekstern (konsumen pengguna produk). Data yang telah terkumpul diolah dengan formula untuk mendapatkan hasil yang dapat digunakan guna pengembangan produk yang diinginkan.

Secara umum dapat dikatakan bahwa QFD merupakan suatu sistem pengembangan produk mulai dari proses perancangan produk, proses pembuatan produk hingga produk tersebut diterima konsumen dan seluruhnya didasarkan atas keinginan konsumen (Widodo, 2005). Dalam penelitian ini yang dimaksud dengan konsumen adalah pengrajin kacang garing yang dalam proses penyangraiannya membutuhkan mesin roaster kacang tanah .

\section{METODOLOGI PENELITIAN}

Konsep QFD (Quality Function Deployment) dikembangkan untuk menjamin bahwa produk yang memasuki tahap produksi benar- benar akan dapat memuaskan kebutuhan para konsumen dengan jalan membentuk tingkat kualitas yang diperlukan dan kesesuaian maksimum pada setiap tahap pengembangan produk.

Fokus utama dari QFD adalah melibatkan konsumen pada proses pengembangan produk sedini mungkin. Filosofi yang mendasarinya adalah bahwa konsumen tidak akan puas dengan suatu produk meskipun suatu produk yang telah dihasilkan dengan sempurna bila mereka memang tidak menginginkan atau membutuhkannya.

Beberapa manfaat yang dapat diperoleh dari QFD bagi perusahaan yang berusaha meningkatkan daya saingnya melalui perbaikan kualitas dan produktivitasnya secara berkesinambungan. Manfaat-manfaat tersebut antara lain:
1. Fokus pada konsumen.

QFD memerlukan pengumpulan masukan dan umpan balik dari konsumen. Informasi tersebut kemudian diterjemahkan ke dalam sekumpulan persyaratan konsumen yang spesifik. Kinerja organisasi dan pesaing dalam memenuhi persyaratan tersebut dipelajari dan diteliti. Dengan demikian organisasi dapat mengetahui sejauh mana organisasi itu sendiri dan pesaingnya memenuhi kebutuhan para konsumen.

2. Efisiensi waktu.

QFD dapat mengurangi waktu pengembangan produk karena memfokuskan pada persyaratan konsumen yang spesifik dan telah teridentifikasi dengan jelas. Oleh karena itu tidak terjadi pemborosan waktu untuk mengembangkan ciri-ciri produk yang tidak atau hanya memberikan sedikit nilai (value) kepada konsumen.

\section{Orientasi Kerja Sama Tim (teamwork- oriented).}

QFD merupakan pendekatan kerjasama tim. Semua keputusan dalam proses didasarkan pada konsensus dan dicapai melalui diskusi mendalam dan brainstorming. Oleh karena setiap tindakan yang perlu dilakukan diidentifikasi sebagai bagian dari proses maka setiap individu memahami posisinya yang paling tepat dalam proses tersebut, sehingga pada gilirannya hal ini mendorong kerja sama tim yang lebih kokoh.

\section{Orientasi Pada Dokumentasi.}

Salah satu produk yang dihasilkan dari proses QFD adalah dokumen komprehensif mengenai mengenai semua data yang berhubungan dengan segala proses yang ada dan perbandingannya dengan persyaratan konsumen. Dokumen ini berubah secara konstan setiap kali ada informasi baru yang dipelajari dan informasi lama yang dibuang. Informasi yang up-to-date mengenai persyaratan konsumen dan proses internal, sangat berguna bila terjadi . 


\section{HASIL DAN PEMBAHASAN}

Pengumpulan data disini dilakukan dengan penelitian survey. Quality Function Deployment merupakan sebuah alat perencanaan yang digunakan untuk memenuhi harapan konsumen terhadap produk. Alat perencanaan utama dalam matriks Quality Fuction Deployment adalah House of Quality (HOQ). Kuisioner dibagikan kepada 30 orang yang semuanya adalah para pekerja proses penyangraian kacang. Kuisioner ini merupakan kuisioner yang dilakukan untuk mengetahui keinginan proses penyangraian kacang terhadap mesin untuk yang sesuai kebutuhan untuk membuat kacang goreng. Kuisioner ini meliputi tingkat kepentingan dan kepuasan para pekerja proses penyangraian kacang (responden) dengan adanya mesin roaster kacang tanah dengan melihat dari berbagai segi.

Adapun faktor-faktor dan formula yang dibutuhkan dalam pengolahan data tersebut dapat diuraikan sebagai berikut:

a) Variabel kebutuhan konsumen terhadap produk, seperti Fungsi, Estetika, Durability, Keamanan, Ergonomis, Ketersediaan komponen dan Ekonomis.

b) Tingkat kepentingan konsumen.

c) Evaluasi produk.

d) Penentuan Nilai Target.

Implementasi QFD terdiri dari tiga tahap diantaranya:

1. Tahap pengumpulan Voice of Customer

2. Tahap penyusunan rumah kualitas (House of Quality)

3. Tahap analisa dan implementasi
Menentukan Atribut Mesin Roaster Kacang Tanah

Dari hasil survey dan penyebaran kuesioner, diperoleh daftar keinginan dan kebutuhan konsumen terhadap Mesin Roaster Kacang Tanah, untuk menentukan importance rating berdasarkan skala likert dengan skala 1 sampai 5, dimana angka 1 menunjukkan least importance dan angka 5 menunjukkan most importance, seperti dapat terlihat pada tabel berikut.

Tabel 1. Atribut Kebutuhan Responden

\begin{tabular}{|c|l|c|}
\hline No & \multicolumn{1}{|c|}{ Atribut } & $\begin{array}{c}\text { Importance } \\
\text { Rating }\end{array}$ \\
\hline 1 & $\begin{array}{l}\text { Proses } \\
\text { penyangraian } \\
\text { cepat }\end{array}$ & 5 \\
\hline 2 & $\begin{array}{l}\text { Hasil matang } \\
\text { merata }\end{array}$ & 5 \\
\hline 3 & $\begin{array}{l}\text { Mudah dan } \\
\text { aman } \\
\text { dioperasikan }\end{array}$ & 5 \\
\hline 4 & $\begin{array}{l}\text { Mudah } \\
\text { perawatan }\end{array}$ & 4 \\
\hline 5 & Hemat biaya & 4 \\
\hline 6 & \begin{tabular}{l} 
Tahan lama \\
\hline 7
\end{tabular} & $\begin{array}{l}\text { Mudah } \\
\text { penggantian } \\
\text { komponen }\end{array}$ \\
\hline 8 & $\begin{array}{l}\text { Mesin mudah } \\
\text { dipindahkan }\end{array}$ & 3 \\
\hline
\end{tabular}

Dengan menggunakan tabel HOQ didapatkan hasil sebagai berikut :

Bahwa kebutuhan konsumen terhadap mesin roaster yang dapat memproses penyangraian kacang tanah yang cepat dan hasilnya matang merata ditunjukkan dengan nilai 390,9 dengan angka relative weight 14,2 . 


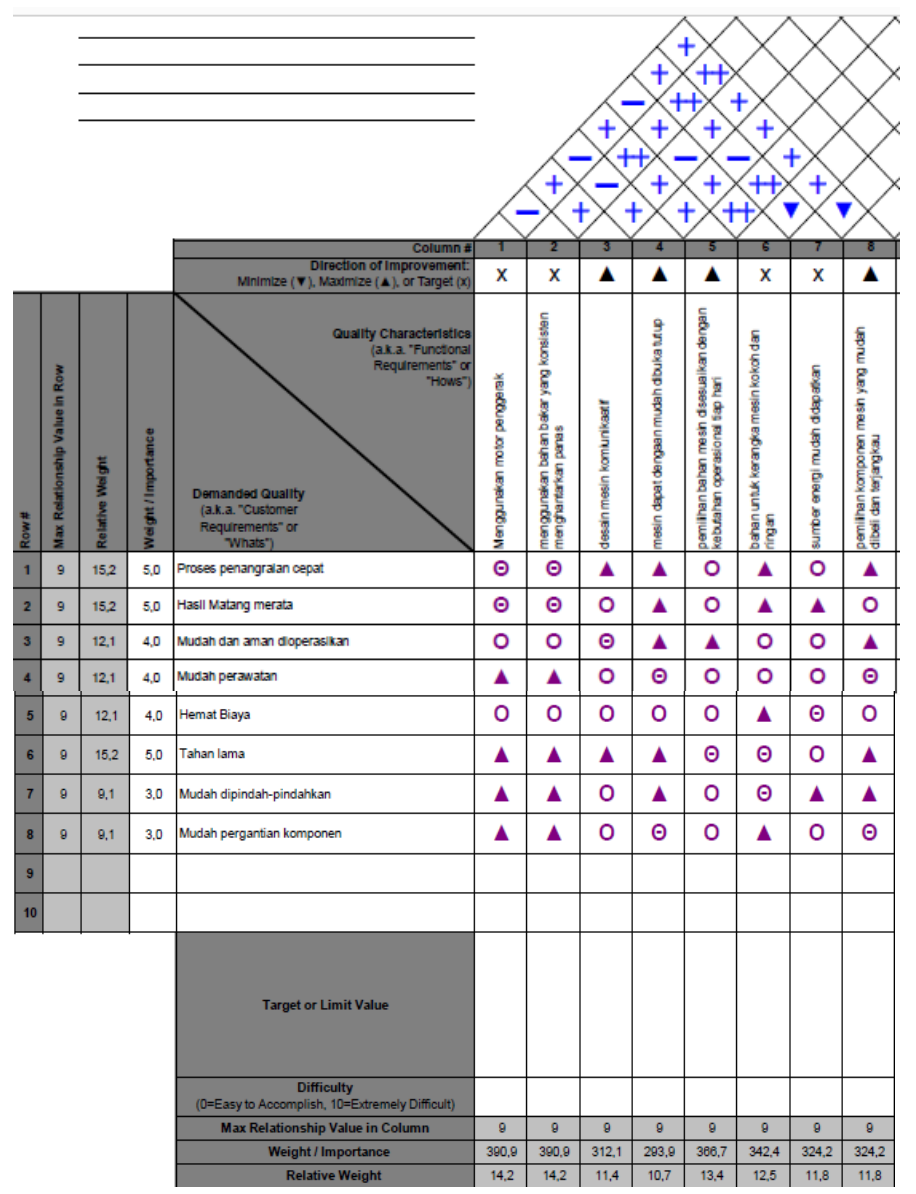

Gambar. 1. Hasil Analisa Mesin Roaster dengan menggunakan HOQ

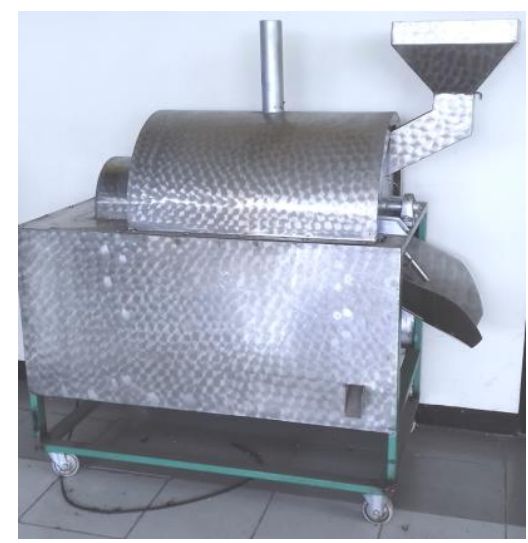

Gambar. 2. Mesin Roaster Kacang Tanah

\section{Spesifikasi Mesin Roaster Kacang Tanah}

Spesifikasi produk meliputi kriteria komponen yang dipergunakan untuk perancangan Mesin Roaster Kacang Tanah sebagai kacang garing. Adapun komponen-komponen yang ada dan dipergunakan pada Mesin Roaster Kacang Tanah sebagai kacang garing adalah sebagai berikut :

\section{a. Corong}

Corong adalah alat yang digunakan untuk menampung bahan berupa kacang tanah untuk sementara waktu, dengan spesifikasi sebagai berikut :

Panjang : $: 28 \mathrm{~cm}$

Lebar $\quad: 28 \mathrm{~cm}$ 
Bahan

: Lembaran Stenless

Kapasitas $: 5 \mathrm{~kg}$

b.Tabung Tertutup

Tabung tertutup adalah alat yang digunakan sebagai penyangrai kacang tanah, dengan spesifikasi sebagai berikut

$\begin{array}{ll}\text { Panjang } & : 64 \mathrm{~cm} \\ \text { Diameter tabung } & : 50 \mathrm{~cm} \\ \text { Bahan } & : \text { Stainnless }\end{array}$

\section{c.Pemanas Kompor Gas}

Pemanas yang digunakan untuk menyangrai kacang tanah ialah kompor gas yang mempunyai spesifikasi sebagai berikut :

$\begin{array}{ll}\text { Panjang } & : 30 \mathrm{~cm} \\ \text { Lebar } & : 15 \mathrm{~cm} \\ \text { Tinggi } & : 10 \mathrm{~cm} \\ \text { Bahan } & : \text { Besi }\end{array}$

\section{d.Rangka Penyangga Mesin}

Rangka penyangga adalah alat yang berfungsi menahan beban dinamis dari mesin. Spesifikasi rangka adalah sebagai berikut :

$\begin{array}{ll}\text { Panjang } & : 100 \mathrm{~cm} \\ \text { Lebar } & : 57 \mathrm{~cm} \\ \text { Tinggi } & : 25 \mathrm{~cm} \\ \text { Bahan } & : \text { Besi }\end{array}$

\section{e.Pengatur Suhu Otomatis}

Pengatur suhu yang di gunakan pada mesin penyangrai ini berfungsi untuk mengatur suhu pemanas agar proses penyangraian lebih efisien. Spesifikasi pengatur suhu ini adalah sebagai berikut:
Panjang : $10 \mathrm{~cm}$
Lebar $\quad: 10 \mathrm{~cm}$
Bahan : Plastik

\section{KESIMPULAN}

Dari hasil kegiatan penelitian yang telah dilaksanakan memberikan kesimpulan :

1. Operasional mesin roaster kacang tanah sebagi kacang goreng ini lebih efisien dan lebih ergomonis di bandingkan dengan mesin lama ( cara manual ).
2. Desain mesin roaster kacang tanah sebagi kacang goreng menciptakan rasa aman dan nyaman bagi operator kerja.

3. Dari mesin roaster kacang tanah sebagi kacang goreng yang baru memiliki memiliki panjang $100 \mathrm{~cm}$, tabung berdiameter $57 \mathrm{~cm}$, dan tinggi $120 \mathrm{~cm}$ diperoleh waktu normal sebesar 16 menit/kg sehingga menghasilkan output standard sebesar $6 \mathrm{~kg} / \mathrm{jam}$. Dengan melihat data-data yang diperoleh jadi didapat kenaikan persentase sebesar $900 \%$. Dengan waktu normal alat lama yang diperoleh dari penelitian sebesar 34 menit / $\mathrm{kg}$ sehingga mendapatkan output standard sebesar $2 \mathrm{~kg} /$ jam.

4. Data antropometri yang dipakai antara lain:

- $\quad$ Tinggi Siku Saat Berdiri

- Jangkauan Tangan Kedepan

- Jangkauan Tangan Kesamping

- Lebar Bahu

DAFTAR PUSTAKA :

[1] Sanny Andjar Sari. 2018. Pengembangan Desain Mesin Penghancur Kotoran Kambing Dengan Menggunakan Metode QFD. Jurnal Teknologi dan Manajemen Industri. Pasca Sarjana Institut Teknologi Nasional Malang.

[2] Sanny Andjar Sari. 2018. Penerapan Ergonomi Pada Mesin Penghancur Guna Peningkatan Produksi Pupuk Organik. Proceeding SENIATI ITN Malang.

[3] Ulrich, Karl T. and Steven D, Eppinger. 2001. Perancangan dan Pengembangan Produk. Jakarta: Salemba Teknik.

[4] Wignjosoebroto, Sritomo. 2003, Ergonomi Study Gerak dan Waktu. Guna Widya Surabaya.

[5] Widodo, Imam Djati, 2005, Perencanaan dan Pengembangan Produk, UII Press, Yogyakarta.William Mendenhall, Statistics for engineering and The Sciences, third edition, Universitas of South Florida. 